\title{
Artificial Project Time Horizons In The Absence Of Discounting: The Case Of Canyon Forest Village
}

Dennis Foster, Northern Arizona University, USA

Craig Bain, Northern Arizona University, USA

\begin{abstract}
In the summer of 1997, the Kaibab National Forest released the Draft Environmental Impact Statement for Tusayan Growth. This report analyzed various scenarios involving the transfer of National Forest land at the boundary of the Grand Canyon National Park to a private developer, in exchange for private inholdings scattered throughout the Kaibab National Forest in northern Arizona. The resulting private development was to be called Canyon Forest Village, and would include hotels, visitor facilities, private housing, community facilities and a transportation center for tourists accessing the Grand Canyon. The proposed build out of Canyon Forest Village (CFV) was to take place from 1999 to 2010. Consequently, the Forest Service analysis used that time frame as the basis for calculating the economic impacts $C F V$ would be expected to have on local economies in the northern Arizona region. The Draft Environmental Impact Statement (EIS) concluded that overall growth in demand for lodging in northern Arizona would be robust over those years, and that CFV would have no net negative impacts. The results of the Draft EIS were sharply contested during the public comment phase, and, in the summer of 1998, a Supplement to the Draft Environmental Impact Statement for Tusayan Growth was issued. This document used a different modeling procedure and changed its primary focus to two, smaller, CFV proposals, involving only 900 and 1,270 hotel rooms. The Supplement did conclude that there would be some negative impacts to the communities surrounding Grand Canyon. The results of the Supplemental Draft EIS were also contested during the public comment phase following its release, although a year later, in the summer of 1999, the Forest Service issued a Final EIS and adopted the CFV proposal for 1,270 rooms. One peculiarity of the Forest Service reports, throughout this process, was the failure to identify an explicit discount rate of interest in order to identify costs and benefits in terms of their present value. While EIS documentation has been required for many years, the obvious focus is on purely environmental concerns and the analyses tend to be based on scientific findings. The inclusion of a socioeconomic analysis necessitates a careful accounting of benefits and costs. While this EIS is not the first to include an explicit accounting of economic benefits and costs, it may serve as a harbinger of more reporting of this type. Unless those with an appreciation of the discounting process, especially economists and accountants, are included in these analyses, present values may be employed only on an erratic basis, making the results of such reports difficult, if not impossible, to adequately interpret. This article applies basic and commonly accepted time value of money principles to an EIS report. Although an economic analysis was provided as part of the report, the time value of money was ignored. In order to present a viable economic impact, these basic financial tenants must be employed. The authors used basic time value of money principles with reasonable discount rates. The result is that impacts could be as much as six times greater than the values given by the Forest Service, representing upwards of one hundred and fifty million dollars.
\end{abstract}

Keywords: Grand Canyon; Economic Impact; Present Value 


\section{INTRODUCTION}

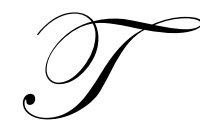

he Grand Canyon national Park runs right through the Kaibab National Forest. As a result, this limits the ability to develop services for the millions of visitors to the Park. In order to attempt to provide more services (food, lodging, etc.) nearer the Park entrance, the Kaibab National Forest has explored various options for getting more private land to open for development.

In the summer of 1997, the Kaibab National Forest released the Draft Environmental Impact Statement for Tusayan Growth (US Department of Agriculture, 1997). This report analyzed various scenarios involving the transfer of National Forest land at the boundary of the Grand Canyon National Park to a private developer, in exchange for several private inholdings scattered throughout the Kaibab National Forest in northern Arizona. The resulting private development was to be called Canyon Forest Village (CFV), and would include hotels, visitor facilities, private housing, community facilities and a transportation center for tourists accessing the Grand Canyon.

CFV was to be located approximately seven miles from the south rim of the Grand Canyon, between the park boundary and the small gateway community of Tusayan. At the time that this Environmental Impact Statement (EIS) was released, there were approximately 1,000 hotel rooms inside the park and 1,000 hotel rooms in Tusayan. The closest communities with additional substantial visitor facilities are Williams, Arizona, with almost 1,400 hotel rooms, and Flagstaff, Arizona, with there are some 4,500 hotel rooms. Williams is about fifty miles from the Grand Canyon, while Flagstaff is about seventy-five miles from the park. The CFV project most heavily promoted by the developer was one that included approximately 3,600 additional hotel rooms.

The proposed build out of CFV was to take place from 1999 to 2010. Consequently, the Forest Service analysis used that time frame as the basis for calculating the economic impacts CFV would be expected to have on local economies in the northern Arizona region. The EIS concluded that (1) overall growth in demand for lodging in northern Arizona would be robust over those years, (2) the displacement of demand to CFV from elsewhere in northern Arizona would be relatively low, and (3) there would be no net negative impacts by 2010. That is, the rest of northern Arizona would continue to grow, but at a somewhat slower rate in the presence of CFV.

The results of the Draft EIS were sharply contested during the public comment phase following the release of this report. The differences between the Forest Service study and its critics have been analyzed by Foster and Bain (2005).

In the summer of 1998, the Kaibab National Forest released a Supplement to the Draft Environmental Impact Statement for Tusayan Growth (U.S. Department of Agriculture, 1998). This document used a different modeling procedure and changed its primary focus to two, smaller, CFV proposals, involving only 900 and 1,270 hotel rooms. The Supplement did conclude that there would be some negative impacts to the communities surrounding Grand Canyon. The results of the Supplemental Draft EIS were also contested during the public comment phase following its release. The shortcomings in the new modeling approach, and the resulting conclusions drawn by the Forest Service have been analyzed by Foster and Bain (2007).

In the summer of 1999, the Forest Service issued a Final EIS and adopted the CFV proposal for 1,270 rooms. However, the issue was not yet settled. The land exchange was contingent upon the rezoning of this land for commercial use. While the Coconino County Board of Supervisors did approve the rezoning request, a referendum drive was launched and the matter placed on the ballot in November of 2000. Voters rejected the rezoning and the land exchange did not take place.

One peculiarity of the Forest Service reports, throughout this process, was the failure to identify an explicit discount rate of interest in order to fully identify costs and benefits in terms of their present value. While EIS documentation has been required for many years, the obvious focus is on purely environmental concerns and the analyses tend to be based on scientific findings. The inclusion of a socioeconomic analysis, which was present in this case, requires a careful accounting of benefits and costs. 
Prior to the issuing of the Draft EIS, officials with the Kaibab National Forest conducted public scoping sessions to help determine what topics needed to be addressed in their report. The Draft EIS is clear on the necessity of a fully developed socioeconomic analysis:

Large-scale development in the Tusayan area could negatively impact the economic base for a number of northern Arizona communities through the loss of Grand Canyon tourist revenue. [Executive Summary of the Draft Environmental Impact Statement for Tusayan Growth, Kaibab National Forest, 1997, p. 5.]

While this EIS is not the first to include an explicit accounting of economic benefits and costs, it may serve as a harbinger of more reporting of this type. Unless those with an appreciation of the discounting process, especially economists and accountants, are included in these analyses, present values may be employed only on an erratic basis, making the results of such reports difficult, if not impossible, to adequately interpret.

\section{THE TIME VALUE OF MONEY}

It is clear that a stream of dollars over time, whether they represent costs or benefits, is not of equivalent value. One reason for this is the presence of inflation. However, in this EIS, all of the diverted spending impacts are calculated from base year values and, consequently, they are expressed in constant dollar terms.

What has not been accounted for in this EIS is the time value of money. A dollar today is worth more than one dollar next year because you don't have to defer the potential use of that dollar for a year. Consequently, to determine the present value of a future dollar, the future dollar must be discounted. Where the EIS calculates diverted spending in 2010, however, this dollar value is not discounted into present value terms. Aggregating a stream of spending impacts requires that this stream be discounted. Indeed, even if there is no explicit discounting, simply adding up values over time does result in implicit discounting. By default, simply adding up dollars across time implies a discount rate of zero, which is difficult to justify.

Failure to use discounting in public decision-making is not unusual. As reported by Zerbe, et.al (Working paper), there is no consistency in governmental use of discount rates and, if used, no consistency in what values are used. Still, some economic analyses can be quite thorough in evaluating what discount rate to use, as was done in the case of the Elwha River Restoration Project (U.S. Bureau of Reclamation, 1995). In that analysis, a review of the literature suggested an appropriate range of discount rates of between $1 \%$ and $4 \%$.

To properly evaluate the socioeconomic impacts of the Canyon Forest Village proposal, we must establish two key parameters:

1. The length of life of the project.

2. The appropriate discount rate to apply to the stream of impacts over this lifespan.

Neither of these parameters was identified in the EIS reports.

\section{PROJECT TIMING IN THE TUSAYAN EIS}

In the Draft EIS, the proposed CFV project would begin construction in 1998, with the first rooms available the following year, in 1999. The final block of rooms would be finished in 2010 and available to the public in that year. The build-out rate is shown in Table 1.

Table 1: Build Out For 3,600 Room Canyon Forest Village

\begin{tabular}{|c|c|c|c|c|c|c|c|c|c|c|c|c|}
\hline Year: & 1999 & 2000 & 2001 & 2002 & 2003 & 2004 & 2005 & 2006 & 2007 & 2008 & 2009 & 2010 \\
\hline Rooms: & 670 & 320 & 680 & 180 & 530 & 180 & 250 & 180 & 180 & 180 & 150 & 150 \\
\hline
\end{tabular}

The Draft EIS only calculated impacts for this build out time period, meaning that rooms available in 1999 would have measurable impacts over 12 years, while rooms finished in 2010 would have a measurable impact over 
only one year. The only justification for ending such an analysis at 2010 was that it represented the end of the construction phase of the project.

From the standpoint of economic theory, and accounting practice, this is untenable. The impacts of the $\mathrm{CFV}$ project are measured, primarily, as the diversion of spending from elsewhere in northern Arizona to Canyon Forest Village. That is, many visitors staying overnight at CFV would have stayed in Tusayan, Williams or Flagstaff. This diverted spending represents lost income in these communities as well as lost tax revenue that would have been generated from this spending. This diverted spending would certainly last beyond 2010 .

If the CFV project has been planned for land privately held, then the impact questions would, by and large, have been moot. That is the way the marketplace functions, and rational economic agents must factor such possibilities into their decision-making. However, in this case, the government is facilitating the creation of private property for a specific developer, with a locational advantage over other, existing, business property owners. Hence, there are policy implications that arise from a full accounting of these socioeconomic impacts.

In the Supplemental Draft EIS, smaller versions of CFV were the focus of attention. Ultimately, a version with 1,270 rooms was approved by the Forest Service. Its build-out rate is shown in Table 2:

Table 2: Build Out For 1,270 Room Canyon Forest Village

\begin{tabular}{|l|c|c|c|c|c|c|c|c|c|c|c|c|}
\hline Year: & 1999 & 2000 & 2001 & 2002 & 2003 & 2004 & 2005 & 2006 & 2007 & 2008 & 2009 & 2010 \\
\hline Rooms: & 0 & 0 & 900 & 370 & 0 & 0 & 0 & 0 & 0 & 0 & 0 & 0 \\
\hline
\end{tabular}

Interestingly, the time frame for analysis remained 1998-2010 even though this version has all rooms built, and available, by 2002. However, this did not reflect a new-found appreciation for the extended impacts of this project. Rather, this time frame was used merely because it represented the longest build-out for the largest version (3,600 rooms) of Canyon Forest Village. That all versions of CFV were analyzed over the same time frame gives the impression of consistency. However, despite this common element, making direct comparisons between the impacts of different versions of CFV would be problematic.

While the time frame chosen ignores diverted consumer spending extending beyond 2010, it also provides the foundation for a downward bias in the calculations of impacts through its use in determining annual visitation to the park. The EIS models calculate Grand Canyon visitation through 2010, the end of the build out time horizon, based on a robust range of growth rates. However, the aggregate growth in visitation is then averaged over this time period to determine annual visitation growth. For example, with an annual growth rate of 2.5\% from 1998 to 2010, an additional 141,556 visitors per year, on average, will be visiting the park.

The import of this result is that more visitors are front-loaded into the model, which mitigates the amount of spending diverted to CFV. For example, in the case of $2.5 \%$ annual visitation growth, the additional visitation would have been barely 120,000 in 2001, more than 20,000 fewer than used in the "averaging" procedure. Clearly, the longer the time frame used for this purpose, the more pronounced is this bias.

\section{ACCUMULATING ECONOMIC IMPACTS}

The Draft EIS does not show cumulative impacts, although it does report values for 2010, without any attempt to discount them into present value terms. The Supplemental Draft EIS does show annual impacts and does aggregate them, without any explicit discounting. As noted, what the EIS reports show is a de facto zero discount rate over the study's time horizon (1998-2010) and an infinite discount rate thereafter. The implied average rate can be calculated from their results if a true time horizon can be specified. For the purposes of this study, we will contrast the impact results when 2010, 2030 and 2050 are used as the end points for the CFV project. These time frames provide some valid milestone comparison points - 2010 is the date used in the EIS, 2030 approximates a twenty year tax system depreciation timeframe, and 2050 represents a forty year useful lifespan for such a capital project. For the purposes of this study, the actual dollar values are unimportant. That is, we are concerned with how 
a proper accounting of present values might magnify these amounts, quite possibly from "is acceptable" to "is not acceptable." Whether the economic impacts have been correctly determined has been addressed in Foster and Bain (2005, 2007). For the purposes of this paper, we have used the dollar values shown in the various EIS reports.

In the Draft EIS, the annual impacts can be calculated, and the cumulative result ascertained, from the results shown in the report. The impacts represent spending diverted from elsewhere in northern Arizona and to Canyon Forest Village when it comprises 3,600 rooms at the end of the project. These values are shown in Table 3. ${ }^{1}$

Table 3: Draft EIS Spending Impacts

\begin{tabular}{|l|l|}
\hline Year & Annual Impact \\
\hline 1998 & $\$ 286,160$ \\
\hline 1999 & $\$ 12,519,500$ \\
\hline 2000 & $\$ 19,494,650$ \\
\hline 2001 & $\$ 32,622,240$ \\
\hline 2002 & $\$ 36,163,470$ \\
\hline 2003 & $\$ 43,281,700$ \\
\hline 2004 & $\$ 44,998,660$ \\
\hline 2005 & $\$ 47,144,860$ \\
\hline 2006 & $\$ 48,253,730$ \\
\hline 2007 & $\$ 49,362,600$ \\
\hline 2008 & $\$ 50,471,470$ \\
\hline 2009 & $\$ 51,115,330$ \\
\hline 2010 & $\$ 51,759,190$ \\
\hline Total & $\$ \mathbf{4 8 7 , 4 7 3 , 5 6 0}$ \\
\hline
\end{tabular}

The figure for 2010, nearly $\$ 52$ million, is the presumed impact that will persist, annually, for the remaining life of the Canyon Forest Village project. So, while the aggregate impact over the time frame of 1998 to 2010, with no discounting, results in a displacement of about $\$ 487$ million dollars, this displacement would continue at $\$ 52$ million in each year thereafter.

In the Supplemental Draft EIS, a different model was used. However, these impacts were shown on an annual basis, and, then, aggregated to the end of the study period, 2010. The results are as shown in Table 4.

Table 4: Supplemental Draft EIS Spending Impacts

\begin{tabular}{|l|l|}
\hline Year & Annual Impact \\
\hline 2001 & $\$ 659,932$ \\
\hline 2002 & $\$ 1,319,864$ \\
\hline 2003 & $\$ 1,979,796$ \\
\hline 2004 & $\$ 2,639,728$ \\
\hline 2005 & $\$ 3,299,660$ \\
\hline 2006 & $\$ 3,959,592$ \\
\hline 2007 & $\$ 4,619,524$ \\
\hline 2008 & $\$ 5,279,456$ \\
\hline 2009 & $\$ 5,939,388$ \\
\hline$\underline{2010}$ & $\$ 6,599,320$ \\
\hline Total & $\mathbf{\$ 3 6 , 2 9 6 , 2 6 0}$ \\
\hline
\end{tabular}

\footnotetext{
${ }^{1}$ It should be noted that while the CFV rooms were not expected to be available until 1999, an artifact of the Forest Service model is that impacts are traceable to 1998. These results are not separated out from the aggregated results. As the 1998 values are relatively small, they have been left in our analysis for the sake of consistency with the Draft EIS report.
} 
As noted, the modeling of impacts was changed in the Supplemental Draft EIS. Casual inspection of Table 4 will show that their reported impacts rise by a constant amount, $\$ 659,932$, every year. This result is due to an increased use of averaging effects over the time frame studied. Consequently, while the results are stated in annual terms, they do not reflect any actual expectation of what these annual impacts are likely to be.

\section{REASSESSING THE CANYON FOREST VILLAGE IMPACTS}

One must presume that the generation of these impact values has some value to decision-makers in the Forest Service. That is, after the Supplemental Draft EIS was published, the relevant policy choice comes down to answering the question, "Is the CFV proposal worth \$36 million of lost spending to the rest of northern Arizona?" Once again, the problem here is that this aggregation represents the sum of a truncated stream of impacts and is not the present value of those impacts.

As noted, the present value of these impacts depend on the lifespan of the project and on the discount rate used. While both of these parameters are unknown, we can pick a range of reasonable outcomes to see the results that follow from applying these basic economic and accounting principles. Using discount rates of 2\%, 3\% and 5\% and evaluating the present value of displaced spending through the years 2010, 2030 and 2050, we get the outcomes shown in Table 5 for both the Draft EIS and the Supplemental Draft EIS.

Table 5: Present Value Of Impacts For Different Discount Rates Over Different Time Horizons

\begin{tabular}{|c|c|c|c|}
\hline \multicolumn{4}{|c|}{ Draft EIS - 3,600 room CFV } \\
\hline & $2 \%$ & $3 \%$ & $5 \%$ \\
\hline 1998-2010 & $\$ 413$ million & $\$ 381$ million & $\$ 327$ million \\
\hline 1998-2030 & $\$ 1,067$ million & $\$ 906$ million & $\$ 669$ million \\
\hline 1998-2050 & $\$ 1,508$ million & $\$ 1,196$ million & $\$ 798$ million \\
\hline \multicolumn{4}{|c|}{ Supplemental Draft EIS - 1,270 room CFV } \\
\hline 1998-2010 & $\$ 31$ million & $\$ 30$ million & \$26 million \\
\hline 1998-2030 & $\$ 120$ million & $\$ 103$ million & $\$ 76$ million \\
\hline 1998-2050 & $\$ 180$ million & $\$ 143$ million & \$96 million \\
\hline
\end{tabular}

Where the Draft EIS shows a cumulative displacement of about $\$ 487$ million (Table 3), if the discount rates are low, $2 \%$ to $3 \%$, and the time horizons are long, 20 to 40 years, the present value of the displacement would be double to triple this amount. Under the same circumstances, in the case of the Supplemental Draft EIS, where the cumulative impacts are given as $\$ 36$ million (Table 4), the present value of these displacements may be five times greater. If the relevant decision-maker is identifying some level of impacts that are acceptable (and this did not happen), one would presume that the difference between $\$ 36$ million and $\$ 180$ million to be unacceptably wide.

\section{CONCLUSIONS}

This article applied basic and commonly accepted time value of money principles to an EIS report. Although an economic analysis was provided as part of the report, the time value of money was ignored. In order to present a viable economic impact, these basic financial tenants must be employed. The authors used basic time value of money principles with reasonable discount rates. The result is that impacts could vary by many multiples over the values given by the Forest Service. In the case of the Supplemental Draft EIS, this difference represents one hundred and fifty million dollars, which represents a four-fold greater impact than that given in the EIS.

\section{AUTHOR INFORMATION:}

Dennis Foster $\mathrm{PhD}$ is a Senior Lecturer at Northern Arizona University. He has testified before the United States Congress on issues related to the Grand Canyon. Dr. Foster is widely recognized as an expert on many Grand Canyon National Park issues. E-mail: Dennis.Foster@nau.edu. 
Craig Bain PhD, CPA is a Professor of Accounting at Northern Arizona University. He has published numerous articles and in been awarded several awards for teaching. E-mail: Craig.Bain@ nau.edu. Corresponding author.

\section{REFERENCES}

1. Foster, Dennis and Bain, Craig, All Roads Lead to ...? An Analysis of the Economic Impact Modeling and the Canyon Forest Village Proposal, The Clarion Business and Economic Review, Volume 5, Number 1 (2005).

2. Foster, Dennis and Bain, Craig, Round Two of the Canyon Forest Village Debate - One Step Forward, Two Steps Back, International Journal of Business Research, (Volume VII Number 6, 2007).

3. The U.S. Bureau of Reclamation, The National Park Service, The Lower Elwha S'Klallam Tribe of Davis, California, "Elwha River Restoration Project: Economic Analysis Final Technical Report", (April, 1995). Also found at: http://faculty.washington.edu/zerbe/docs/discount rates/

4. U.S Department of Agriculture, Kaibab National Forest, Supplement to the Draft Environmental Impact Statement for Tusayan Growth, (1998).

5. U.S Department of Agriculture, Kaibab National Forest, Draft Environmental Impact Statement for Tusayan Growth, (1997).

6. Zerbe, Richard, Xi Han, David Layton, and Tom Leshine., “ A History of Discount Rates and Their Use by Government Agencies" Unpublished Working Paper, (2002), can be found at: http://faculty.washington.edu/zerbe/docs/discount_rates/ 
NOTES 